\title{
The role of anxious temperament in patients with allergic rhinitis
}

Halil Ibrahim Tas, MD, Ozge Caglar, MD.

\begin{abstract}
الأهداف : تقويم مستويات الاكتئاب والقلق في التهاب الأنف

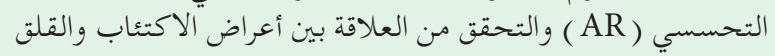
وميزات مزاجية الاكتئاب والقلق .

الطريقة: صممت دراسة مستعرضة . وأجريت الدراسة المستعرضة

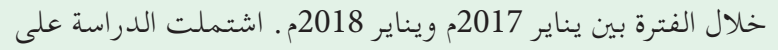

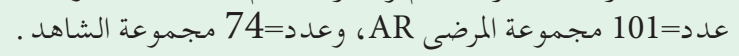

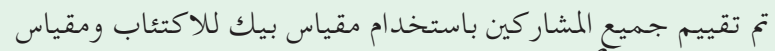
بيك للقلق و TEMPS_A (Temperament Evaluation of Memphis، Pisa، Paris، San Diego (Autoquestionaire

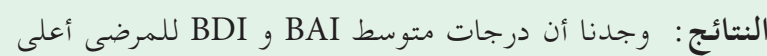
بشكل إحصائي من مجموعة التحكي أنم درجات (

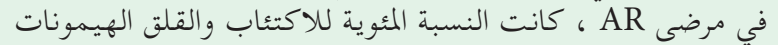
أعلى بكثير من المجموعة الضابطة (

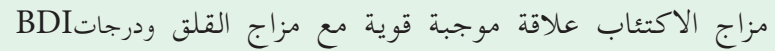
وعلاقة متوسطة مع BAI r ؛

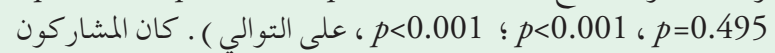

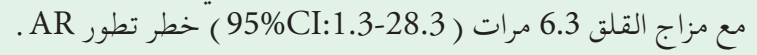
الخاتمة : قد يسمح فحص سمات المزاج في مرضى AR بالتنبؤ بأعراض

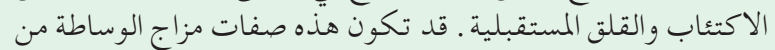

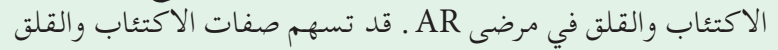

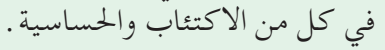

Objectives: To evaluate the depressive and anxiety levels in allergic rhinitis (AR) and to investigate the relationship between depression and anxiety symptoms and depressive and anxious temperament features.

Methods: The study design is cross-sectional. The study was conducted between January 2017 and January 2018. Patients $(\mathrm{n}=101)$ diagnosed with AR and healthy controls $(n=74)$ were included in this study. All participants were assessed with the
Beck Depression Inventory (BDI), Beck Anxiety Inventory (BAI), and TEMPS-A (Temperament Evaluation of Memphis, Pisa, Paris, San Diego Autoquestionaire).

Results: The median BAI and BDI scores of the patients were found to be significantly higher than the control group ( $p=0.016$ and $p=0.001$ ). In AR patients, the percentage of depressive and anxious temperaments were significantly higher than in the control group $(p=0.029)$. Depressive temperament scores showed strong positive correlation with anxious temperament and BDI scores and a medium relationship with the BAI $(r ; p=0.639$; $p<0.001, p=0.671 ; p<0.001$, and $p=0.495 ; p<0.001$, respectively). Participants with anxious temperament had 6.3-times (95\% CI: 1.3-28.3) the risk for developing AR.

Conclusion: Screening of temperament traits in AR patients may allow prediction of future depression and anxiety symptoms. These temperament traits may be mediators of depression and anxiety in AR patients. Depressive and anxious temperament traits may contribute to both depression and allergy.

Saudi Med J 2019; Vol. 40 (1): 45-51

doi: 10.15537/smj.2019.1.23754

From the Department of Psychiatry (Tas) and the Department of Otolaryngology (Caglar), Canakkale Onsekiz Mart University, Canakkale, Turkey.

Received 17th August 2018. Accepted 13th November 2018.

Address correspondence and reprint request to: Dr. Halil I. Tas, Department of Psychiatry, Canakkale Onsekiz Mart University, Canakkale, Turkey. E-mail:tashalilibrahim@gmail.com

ORCID ID: orcid.org/0000-0001-5849-9068

Alergic rhinitis (AR) is an inflammatory disease Athat develops as a hypersensitivity reaction of the immunoglobulin $\mathrm{E}$ in the nasal mucosa, causing symptoms such as nasal discharge, sneezing, and nasal obstruction. The disease has a worldwide prevalence of approximately $10-30 \% .{ }^{1}$ This reaction may be caused 
by allergenic substances such as pollens, house dust mites, molds, and pests. ${ }^{2}$ Especially in recent years, the sensitivity to allergens has increased with an increase in the prevalence of $\mathrm{AR}^{3}$ Studies have shown that mental disorders are more common in AR patients than in the ordinary population. In particular, the rates of depression, anxiety, and sleep disturbance are higher in patients with AR than in the general population. ${ }^{4-6}$ It has even been reported that depression and suicidal behavior may be more common among individuals with AR. ${ }^{7}$ The role of depression and anxiety as psychopathologies in patients with $A R$ and whether this psychopathology is a cause or effect are still much sought after questions. ${ }^{8,9}$

There are 2-way interactions between allergic disorders and psychological states, in which many genetic and environmental factors, as well as stressors that can affect the mood, are involved. ${ }^{10}$ There is an impairment of immunological responses of individuals predisposed to allergic disorders such as $A R$ with a dominance towards differentiation into CD4 + T helper 2 (Th 2). As a result of this differentiation, depressed individuals may have similar neuroinflammatory markers observed in AR that may trigger allergies via mediators such as IL-4, IL-5, and IL-6. ${ }^{11,12}$ All these factors can affect the psychopathology in individuals with AR in ways such as depression and anxiety. However, the pathophysiological connection of this process is still not clear.

Alternatively, genetic, neurobiological, and environmental factors play an essential role in the etiology of mood disorders, such as depression and bipolar disorders. Some studies in the last decade have confirmed that affective temperaments are subthreshold clinical forms of classical mood disorders, which predispose to mood disorders. ${ }^{13-17}$ An affective temperament is a highly inherited phenomenon that defines an individual's level of activity, rhythms, mood, and related cognition, which defines the underlying biological and genetic tendency of the person and automatically gives an emotional response to events. Affective temperament traits are psychiatric phenomena that can help predict and define susceptibility to depression. ${ }^{16,17}$ Parallel to increasing frequencies of depression and anxiety, along with other psychiatric illnesses in individuals with allergic problems, studies

Disclosure. Authors have no conflict of interests, and the work was not supported or funded by any drug company. have been conducted in recent years to evaluate temperament properties in individuals with allergic diseases, taking into consideration the causative role of temperaments in these diseases. ${ }^{18-20}$ Temperament traits are reported as related to the functioning of the human autonomous and immune system and have a determining role in how the body responds to external stimuli. ${ }^{21}$ It is known that depressed patients have a disturbed immune system ${ }^{22}$ and there are subclinical phenomena that can determine the susceptibility of affective temperaments to depressive and anxiety disorders. Thus, we think that specific temperament traits may be important in the development of depressive and anxiety symptoms common in AR patients. In this context, our primary aim was to evaluate the levels of depression and anxiety in AR; our secondary aim was to evaluate the causative roles of depressive and anxious temperament characteristics in the development of depressive and anxiety symptoms in patients with AR.

Methods. This case-control study included $101 \mathrm{AR}$ patients who were consecutively referred to the Ear Nose and Throat (ENT) Polyclinics at the Çanakkale Onsekiz Mart University Medical School, Çanakkale, Turkey between January 2017 and January 2018, as the study group, and 74 non-allergic, physically and psychiatrically healthy people as the control group. All participants were examined by the same ENT specialist. An endoscopic nasal examination was performed on all participants, and in addition to their clinical complaints, patients with pale nasal mucosa and decongestant findings were invited to join the study.

The inclusion criteria for the study group were patients above 18 years old and diagnosed with AR by the clinician. The exclusion criteria for the study group were patients having a chronic disease other than AR, mental disability, or psychotic disorder. Of the 108 people who met the inclusion criteria for the AR group, 4 patients refused to participate in the study and 3 were excluded because they could not complete the scales.

The control group consisted of volunteers who were healthy individuals without any AR symptoms, known physical diseases, intellectual disabilities, psychiatric disorders, or medication use in the last month. The ethical board of the Çanakkale Onsekiz Mart University Medical School, Çanakkale, Turkey approved the study $(02.11 .2016 / 19)$ and the study was conducted in accordance with the declaration of Helsinki. In addition to collecting sociodemographic data, the participants were asked to complete the Beck Depression Inventory (BDI) to measure depression, the Beck Anxiety Inventory (BAI) to 
measure anxiety, and the TEMPS-A (Temperament Evaluation of Memphis, Pisa, Paris, France, San Diego Autoquestionaire) questionnaire.

The BDI was developed Beck et al, ${ }^{23}$ aiming to suspect depression and measure its severity. The scale consists of 21 items, questions concerning the cognitive, physical, and behavioral symptoms of depression. Beck Anxiety Inventory is one of the most commonly used measurement tools for psychiatric patients and the general population to assess the symptoms and intensity of depression. While the BAI is a self-assessment scale developed by Beck et al to determine the frequency of experienced anxiety symptoms. It is a Likert-type measure consisting of 21 items, scored between 0 and $3 .{ }^{24}$

The TEMPS-A scale was developed by Akiskal et $\mathrm{a}^{25}$ to measure the dominant affective temperament. The original scale has 110 items for women and 109 items for men.

Statistical analysis. Analysis of the data was carried out using Statistical Package for the Social Sciences (SPSS) Package Program version 20.0. The descriptive presentation of the data was attained as frequency, percentage, mean and standard deviation, median, minimum, and maximum values. Depending on the number of patients in the groups, normal distribution of the variables was assessed by the Kolmogorov Smirnov test or the Shapiro-Wilk test. The independent samples t-test or the Mann Whitney $U$ test were used to compare continuous variables between groups. The Chi-square test was employed to compare categorical variables between the groups. A $p$-value below 0.05 was considered statistically significant. The relationship between TEMPS-A temperament subtype scores and anxiety and depression scale scores was examined by the Spearman correlation analysis. In the evaluation of the correlation, 0.00-0.24 was defined as a weak relationship; $0.25-0.49$ as medium; $0.50-0.74$ as strong; and $0.75-1.00$ as very strong. ${ }^{26}$ Factors affecting the development of AR were evaluated by the logistic regression analysis with a backward conditional model. The presence or absence of AR was defined as the dependent variable, while anxious temperament, depressive temperament, BAI scores, and BDI scores were used as independent variables.

Results. The mean age of the study group $(\mathrm{n}=175)$ was $31.36 \pm 8.19$ years (median: 30.00, $\min : 19.00$, and max: 57.00). Data on age and other continuous variables of the study group are presented in Table 1 . There was no statistically significant difference between the patient and control groups concerning gender and age. The median BAI and BDI scores of the patients were significantly higher than the control group ( 11.00 versus $9.00, p=0.016$, and 10.00 versus $5.00, p=0.001$, respectively).

When the patients and control groups were examined in terms of temperament types, the percentage of depressive temperament individuals was significantly higher in patients with AR compared to the control group ( $23.8 \%$ versus $10.8 \%, p=0.029)$. Anxious temperament was significantly higher in the patient group than in the control group (14.9 versus $2.7 \%, p=0.008$ ) (Table 2). When other temperament types were examined, no cyclothymic or hyperthymic dominant temperament was present in the patient group. There were 5 participants with irritable temperament in the control group and 3 participants

Table 1 - Comparison of age, gender and beck depression inventory scores of the patient and control groups.

\begin{tabular}{|c|c|c|c|c|}
\hline Variables & $\begin{array}{l}\text { Patient group } \\
(\mathrm{n}=101)\end{array}$ & $\begin{array}{l}\text { Control group } \\
(n=74)\end{array}$ & $P$-value & $x^{2}$ \\
\hline Gender (\%) & & & $0.709^{*}$ & 0.139 \\
\hline Female & $64(63.4)$ & $43(60.6)$ & & \\
\hline Male & $37(36.6)$ & $28(39.4)$ & & \\
\hline Age (years) & & & $0.205^{\dagger}$ & -1.267 \\
\hline Mean \pm SD & $32.03 \pm 8.31$ & $30.45 \pm 8.00$ & & \\
\hline Median (min-max) & $32.00(19.00-57.00)$ & $28.00(20.00-51.00)$ & & \\
\hline Beck anxiety score & & & $0.016^{\dagger}$ & -2.405 \\
\hline Mean \pm SD & $15.93 \pm 13.61$ & $10.91 \pm 10.06$ & & \\
\hline Median (min-max) & $11.00(0.00-59.00)$ & $9.00(0.00-42.00)$ & & \\
\hline Beck depression score & & & $0.001^{\dagger}$ & -3.304 \\
\hline Mean \pm SD & $13.70 \pm 12.67$ & $8.18 \pm 8.99$ & & \\
\hline Median (min-max) & $10.00(0.00-55.00)$ & $5.00(0.00-43.00)$ & & \\
\hline
\end{tabular}


Table 2 - Comparison of patient and control groups regarding TEMPS-A temperament types.

\begin{tabular}{lrrrrrr}
\hline Variables & \multicolumn{2}{c}{$\begin{array}{c}\text { Patient group } \\
(\mathbf{n}=101)\end{array}$} & $\begin{array}{c}\text { Control } \\
\text { group } \\
(\mathbf{n = 7 4 )}\end{array}$ & $P$-value & $x^{2}$ \\
\hline Depressive & 24 & $(23.8)$ & 8 & $(10.8)$ & & \\
Not depressive & 77 & $(76.2)$ & 66 & $(89.2)$ & 0.046 & 3.967 \\
Anxious & 15 & $(14.9)$ & 2 & $(2.7)$ & & \\
Not anxious & 86 & $(85.1)$ & 72 & $(97.3)$ & 0.015 & 5.869 \\
\hline \multicolumn{6}{c}{ Values are presented as numbers and percentage (\%). } \\
\multicolumn{6}{c}{ TEMPS-A - Temperament Evaluation of Memphis, Pisa, Paris, France, } \\
\multicolumn{6}{c}{ San Diego Autoquestionaire } \\
\hline
\end{tabular}

with irritable temperament in the patient group. Results of the correlation analysis. The relationship of the continuous variables with each other in the study group was examined with the Spearman correlation analysis. Depressive temperament scores showed strong positive correlation with anxious temperament scores as well as BDI scores and a medium relationship with the BAI ( $\mathrm{r} ; p=0.639 ; p<0.001, p=0.671 ; p<0.001$, and $p=0.495$; $p<0.001$, respectively). There was a strong positive correlation between anxious temperament, BDI, and BAI scores $(p=0.554 ; p<0.001$ and $p=0.543 ; p<0.001)$. The correlations between the temperament subtypes and BAI and BDI scores are presented in Table 3.

Risk factors affecting the development of AR were evaluated using Logistic Regression Analysis. The dependent variable was the presence of AR. Anxious temperament, depressive temperament, BAI score, and BDI score were included in the model as independent variables. The presence of anxious temperament constituted 6.3 times more risk for having $\operatorname{AR}(p=0.017$, $\mathrm{B}=1.837,95 \%$ CI $1.390-28.374$ ).

Discussion. We found significantly higher anxiety and depression scores in the AR group compared to the control group. The role of psychological factors in allergic diseases has been a recent topic of debate and is still being studied in areas such as psychoimmunology and psychodermatology. Individuals' mental status, personality structure, and psychosocial factors are reported to exacerbate allergic conditions, and may even be a predisposing factor to allergic diseases. There is a bilateral causal relationship between the mood of the person and allergic diseases. ${ }^{10}$ As a matter of fact, a recent meta-analysis reported that allergic disorders are associated with a high risk of depression. The analysis of 1972 studies reported that patients with asthma and AR had a higher risk of depression than patients with other allergic disorders. In sub-group analyses based on age and gender, it was reported that the risk of depression in children, adults, and females was higher. ${ }^{27}$ Heffner et $\mathrm{al}^{28}$ examined the effect of stress and anxiety on skin test responses in individuals with AR. They reported that individuals with atopic and high levels of anxiety have more skin test response to antigens that were previously negative after the stress test. ${ }^{28} \mathrm{~A}$ study evaluating the association between suicide with allergies reported that there is a greater degree of allergies among those with a history of depression, an increase in the rate of suicide among allergic individuals, and parallelism between peak periods of allergies and peak suicide attempts. $^{7}$ Psychological stress and depressive mood may be associated with increased inflammatory markers as well as with improvement and control of allergic disorders in depression. ${ }^{29}$ Similar to the mentioned studies, higher levels of depression and anxiety were found in individuals with AR in our study. However, we do not yet have sufficient explanatory information about why depressive and anxiety symptoms are more common in $\mathrm{AR}$ patients.

Another finding of our study is that the individuals with a depressive and anxious temperament in the AR group were found to have significantly higher temperament traits predisposed to depression compared to the control group. Considering that affective temperament characteristics are accepted as subthreshold clinical indications of mood disorders, ${ }^{14}$ and specific temperament types are premise of mood disorders, ${ }^{15}$

Table 3 - Correlation of TEMPS-A subscale, BAI, and BDI scores in the patient group.

\begin{tabular}{|c|c|c|c|c|c|c|c|c|}
\hline \multirow{2}{*}{$\begin{array}{l}\text { Variables } \\
\text { Depressive temperament }\end{array}$} & \multicolumn{2}{|c|}{$\begin{array}{c}\text { Depressive } \\
\text { temperament }\end{array}$} & \multicolumn{2}{|c|}{$\begin{array}{c}\text { Anxious } \\
\text { temperament }\end{array}$} & \multicolumn{2}{|c|}{$\begin{array}{c}\text { BAI } \\
\text { score }\end{array}$} & \multicolumn{2}{|c|}{$\begin{array}{l}\text { BDI } \\
\text { score }\end{array}$} \\
\hline & - & - & $0.639^{\dagger}$ & $<0.001$ & $0.495^{\dagger}$ & $<0.001$ & $0.671^{\dagger}$ & $<0.001$ \\
\hline Anxious temperament & $0.639^{\dagger}$ & $<0.001$ & - & - & $0.543^{\dagger}$ & $<0.001$ & $0.554^{\dagger}$ & $<0.001$ \\
\hline BAI score & $0.495^{\dagger}$ & $<0.001$ & $0.543^{\dagger}$ & $<0.001$ & - & - & $0.655^{\dagger}$ & $<0.001$ \\
\hline BDI score & $0.671^{\dagger}$ & $<0.001$ & $0.554^{\dagger}$ & $<0.001$ & $0.655^{\dagger}$ & $<0.001$ & - & - \\
\hline
\end{tabular}


it becomes more important that these temperament features are frequent among $\mathrm{AR}$ patients. It has been reported that cyclothymic, depressive, and anxious temperaments are strongly associated with depressive heredity, and individuals with mood disturbances in their family history also have twice the likelihood of a dominant affective temperament in the family history. ${ }^{30}$ Although there have been no previous studies evaluating temperament properties in AR patients, research conducted in other allergic patients may provide information to understand the relationship between temperament, AR, and depression. Indeed, in a study in which patients with chronic idiopathic urticaria were compared with healthy subjects using the Temperament and Character Inventory, it was reported that patients with urticaria had higher novelty-seeking scores than the control group, and lower cooperativeness, selftranscendence, and reward-dependence scores. In this study, it was also stated that some neurotransmitters, such as serotonin and dopamine, may explain the relationship between temperament and urticaria. ${ }^{20}$ Temperament and character traits were compared with the control group in the study of atopic dermatitis, an allergic disease, which usually starts in childhood or adolescence. ${ }^{31}$ Participants in the atopic dermatitis group had higher harm avoidance scores and lower reward dependence and self-transcendence scores. A negative correlation between reward dependence and depression scores suggests that the depression in atopic dermatitis may be associated with the neuroadrenergic system. ${ }^{31}$ In a study comparing patients with bronchial asthma to healthy controls and assessing coping with temperament and stress, it was reported that the "vitality" temperament type was lower in the asthma group compared to the control group and there was no difference between the other temperament traits. ${ }^{19}$ In a study comparing adolescent AR with diabetic controls, Adamia et $\mathrm{a}^{32}$ investigated the psychological and emotional profiles of adolescents with the Eysenck Personality Questionnaire. In adolescents with AR, interpersonal susceptibility, hostile attitudes, and impulsive traits emerged. It has been reported that AR is characterized by depression, poor compliance, low resistance to stress, and unstable temperament. ${ }^{32}$

Although there are no studies evaluating the relationship between temperament and depression in AR patients, studies with different assessment tools in other allergic patient samples reveal important data that show temperament traits are structural features predisposing to depression in this patient group. Indeed, in our study we found that the anxious and depressive mood measured by the Affective Temperament Scale, a more appropriate assessment tool for mood disorders, predisposes to depression in AR patients. Considering the relationship between temperaments, the immune system, and depression, ${ }^{21}$ it is thought that these temperament traits may play a decisive role in determining depression susceptibility in AR patients. Thus, in AR patients with depressive and anxious temperament characteristics, more careful monitoring and prevention of depression may help prevent possible unnecessary suffering.

We found that individuals with anxious temperament had a 6.3-times higher risk for AR than those who did not have anxious temperament. A meta-analytic study of the relationship between atopy and psychosocial factors showed that psychosocial factors have both etiologic and prognostic effects on atopic disorders. Considering the inflammatory responses in asthma and depression, it is reported that inflammation continuing in the allergic process may be a bridge connecting these 2 diseases, and that cytokines can mediate this bridge by modulating inflammatory responses. ${ }^{33}$ Genetic factors play an important role in the development of $\mathrm{AR}$ (atopy and allergic predisposition) as well as in the formation of temperament traits that are components of the personality emerging as the child's behaviors from birth. ${ }^{34,35}$

In light of this information, considering that temperament traits are inherent (and thus undergo little change throughout life) and are powerful predictors of psychopathology, it can be postulated especially depressive and anxious temperament characteristics contribute to the development of depression and allergy, which have a causative relationship.

Considering all our findings: we think that both higher depression and anxiety scores in AR patients compared to healthy controls, as well as high depression and anxiety as dominant temperaments, will shed light on future research concerning the etiology of the disease in the axis of temperament characteristics.

Study limitations. Due to the cross-sectional nature of the collected data, temporal relationships between the conditions cannot be determined. In addition, by evaluating the self-reported status of the participants, the study is also subjected to recall bias. Drug use in the AR group was not excluded, which may have affected anxiety and depression scores in that group. Another important limitation was the insufficient evaluation of the confounding effect of having a chronic disease and use of medication, since the control group is composed of completely healthy individuals. Our study was able 
to assess the complex relationship between $\mathrm{AR}$ and mental health in the general adult population.

In this study, not only the anxiety and depressive symptoms, but also the dominant depressive and anxiety temperaments were found to be higher in AR patients compared to the control group. We think that predicting temperament traits in AR patients may allow for the prediction of future depression and anxiety symptoms; that is, these temperament traits can be regarded as mediators of depression and anxiety in these patients. However, it is difficult to establish this causative relationship with a cross-sectional design. Temperamental screening can be useful in disease models of $\mathrm{AR}$, as well as prevention, intervention, and treatment. Therefore, we believe that long-term follow-up studies evaluating common etiologic pathways such as inflammation would be beneficial.

Acknowledgment. We would like to thank EditMyEnglish Bellevue, WA, USA for editing the manuscript.

\section{References}

1. Cingi C, Gevaert P, Mösges R, Rondon C, Hox V, Rudenko M, et al. Multi-morbidities of allergic rhinitis in adults: European Academy of Allergy and Clinical Immunology task force report. Clinical and Translational Allergy 2017; 7: 17.

2. Seidman MD, Gurgel RK, Lin SY, Schwartz SR, Baroody FM, Bonner JR, et al. Clinical Practice Guideline: Allergic Rhinitis. Otolaryngol Head Neck Surg 2015; 152: 1-43.

3. Wheatley LM, Togias A. Allergic Rhinitis. N Engl J Med 2015; 372: 456-463.

4. Chen MH, Su TP, Chen YS, Hsu JW, Huang KL, Chang $\mathrm{WH}$, et al. Allergic rhinitis in adolescence increases the risk of depression in later life: a nationwide population-based prospective cohort study. J Affective Disord 2013; 145: 49-53.

5. Xi L, Zhang Y, Han D, Zhang L. Effect of asthma, aeroallergen category, and gender on the psychological status of patients with allergic rhinitis. J Investig Allergol Clin Immunol 2012; 22: 264-269.

6. Kim DH, Han K, Kim SW. Relationship between allergic rhinitis and mental health in the general Korean adult population. Allergy Asthma Immunol Res 2016; 8: 49-54.

7. Amritwar AU, Lowry CA, Brenner LA, Hoisington AJ, Stiller JW, Hamilton R, et al. Mental health in allergic rhinitis: depression and suicidal behavior. Curr Treat Options Allergy 2017; 4: 71-97.

8. Özmen M, Özdemir A. Alerjik Rinit ve Ruhsal Sorunlar. Turkiye Klinikleri Journal of Internal Medical Sciences 2006; 2: 23-28.

9. Trikojat K, Luksch H, Rösen-Wolff A, Plessow F, Schmitt J, Buske-Kirschbaum A. "Allergic mood"- depressive and anxiety symptoms in patients with seasonal allergic rhinitis (SAR) and their association to inflammatory, endocrine, and allergic markers. Brain Behavior and Immunity 2017; 65: 202-209.

10. Başoğlu C, Durmaz O. The role of psychological factors in allergic diseases. Turkiye Klinikleri J Fam Med-Special Topics 2011; 2: 95-100.
11. Abbas AK, Murphy KM, Sher A. Functional diversity of helper T lymphocytes. Nature 1996; 383: 787-793.

12. Dowlati Y, Herrmann N, Swardfager W, Liu H, Sham L, Reim $\mathrm{EK}$, et al. A meta-analysis of cytokines in major depression. Biol Psychiatry 2010; 67: 446-457.

13. Angst J. Temperament and personality types in bipolar patients a historical review. In: Marneros A, Angst J editors. Bipolar disorders. Dordrecht (Lodon), Springer; 2000. p.175-199.

14. Akiskal HS, Akiskal KK, Haykal RF, Manning JS, Connor PD. TEMPS-A: progress towards validation of a self-rated clinical version of the Temperament Evaluation of the Memphis, Pisa, Paris, and San Diego Autoquestionnaire. J Affect Disord 2005; 85: 3-16.

15. Rihmer Z, Akiskal KK, Rihmer A, Akiskal HS. Current research on affective temperaments. Curr Opin Psychiatry 2010; 23: 12-18.

16. Kesebir S, Gündoğar D, Küçüksubaşı Y, Yaylacı ET. The relation between affective temperament and resilience in depression: a controlled study. J Affect Disord 2013; 148: 352-356.

17. de Aguiar Ferreira A, Vasconcelos AG, Neves FS, Correa, H. Affective temperaments and antidepressant response in the clinical management of mood disorders. J Affect Disord 2014; 155: 138-141.

18. Gulec MY, Gulec H, Oztuna F, Kose S. Cloninger's temperament and character dimension of personality in patients with asthma. Int J Psychiatry Med 2010; 40:273-287.https://doi. org/10.2190/PM.40.3.d

19. Panek M, Kuna P, Witusik A, Wujcik R, Antczak A, Pietras T. Temperament and stress coping styles in bronchial asthma patients. Postepy Dermatol Alergol 2016; 33: 469-474.

20. Alan S, Canan F, Karakaş AA, Geçici N. Temperament and character profiles of patients with chronic idiopathic urticaria. Postepy Dermatol Alergo 2015; 32: 167-172.

21. O'Connor TG, Scheible K, Sefair AV, Gilchrist M, Blackmore $\mathrm{ER}$, Winter MA, et al. Immune and neuroendocrine correlates of temperament in infancy. Dev Psychopathol 2017; 29: 1589-1600.

22. Dowlati Y, Herrmann N, Swardfager W, Liu H, Sham L, Reim EK, et al. A meta-analysis of cytokines in major depression. Biol Psychiatry 2010; 67: 446-457.

23. Beck AT, Ward CH, Mendelson M, Mock J, Erbaugh J. An inventory for measuring depression. Arch Gen Psychiatry 1961; 4:561-571.

24. Beck AT, Epstein N, Brown G, Steer RA. An inventory for measuring clinical anxiety: Psychometric properties. J Consult ClinPsychol 1988; 56: 893-897.

25. Akiskal HS, Placidi GF, Maremmani I, Signoretta S, Liguori A, Gervasi R, et al. TEMPS-I: delineating the most discriminant traits of the cyclothymic, depressive and irritable temperaments in a nonpatient population. J Affect Disord 1998; 51: 7-19.

26. Aksakoğlu G. Health Research Methods and Methods of Analysis. İzmir (TR): D.E.Ü. Rektörlük Matbaası; 2001. Turkish.

27. Lu Z, Chen L, Xu S, Bao Q, Ma Y, Guo L, et al. Allergic disorders and risk of depression: A systematic review and metaanalysis of 51 large-scale studies. Ann Allergy Asthma Immunol 2018; 120: 310-317.

28. Heffner KL, Kiecolt-Glaser JK, Glaser R, Malarkey WB, Marshall GD. Stress and anxiety effects on positive skin test responses in young adults with allergic rhinitis. Annals of Allergy, Asthma \& Immunology 2014; 113: 13-18. 
29. Brown ES, Sayed N, Van Enkevort E, Kulikova A, Nakamura A, Khan DA, et al. A randomized, double-blind, placebocontrolled trial of escitalopram in patients with asthma and major depressive disorder. The Journal of Allergy and Clinical Immunology: In Practice 2018; 6: 1604-1612.

30. Lazary J, Gonda X, Benko A, Gacser M, Bagdy G. Association of depressive phenotype with affective family history is mediated by affective temperaments. Psychiatry Res 2009; 168: 145-152.

31. Kim TS, Pae CU, Jeong JT, Kim SD, Chung KI, Lee C. Temperament and character dimensions in patients with atopic dermatitis. J Dermatol 2006; 33: 10-15.

32. Adamia N, Jorjoliani L, Manjavidze N, Ubiria I, Saginadze L. Psycho-emotional characteristics of the adolescents with allergic rhinitis. Georgian Med News 2015; 6: 38-42.
33. Jiang M, Qin P, Yang X. Comorbidity between depression and asthma via immune-inflammatory pathways: a meta-analysis. $J$ Affect Disord 2014; 166: 22-29.

34. Lester N, Garcia D, Lundström S, Brändström S, Råstam M, Kerekes N, et al. The genetic and environmental structure of the character sub-scales of the temperament and character inventory in adolescence. Annals of General Psychiatry 2016; 15: 10 .

35. Portelli MA, Hodge E, Sayers I. Genetic risk factors for the development of allergic disease identified by genome区wide association. Clinical and Experimental Allergy 2015; 45: 21-31. 